\title{
IMPACTOS DA PANDEMIA DE COVID-19 NOS TRABALHOS DE CAMPO DAS PESQUISAS GEOGRÁFICAS
}

\author{
Andrea César da Silveira ${ }^{1}$ \\ Frederico de Holanda Bastos²
}

Resumo: Este artigo apresenta um panorama dos impactos negativos provocados pela pandemia de Covid-19 nas pesquisas de pós-graduação em Geografia no Brasil, considerando o período compreendido entre março de 2020 e fevereiro de 2021. O objetivo foi tentar verificar quais os principais impedimentos para a realização dos trabalhos de campo e as possíveis adaptações. Para tanto, realizamos uma coleta de dados por meio de formulários elaborados na plataforma digital Google Forms, encaminhados via correio eletrônico. Obteve-se a participação de 207 alunos, referentes a 18 programas de pós-graduação, das cinco regiões do país. Os resultados revelaram que $59,4 \%$ dos alunos suspenderam totalmente as atividades de campo nos primeiros 12 meses da pandemia, enquanto outros tiveram que tomar decisões drásticas, incluindo a exclusão do trabalho de campo. A prorrogação de prazos se faz necessária para a conclusão das pesquisas, notadamente daquelas onde não houve possibilidades de ajustes e adaptações.

Palavras-chave: Pós-graduação, Conhecimento geográfico, Crise de saúde pública.

\section{IMPACTS OF THE COVID-19 PANDEMIC ON THE FIELDWORK OF GEOGRAPHICAL RESEARCH}

Abstract: This article presents an overview of the negative impacts caused by the Covid-19 pandemic in postgraduate research in Geography in Brazil, considering the period between March 2020 and February 2021. The objective was to try to verify the main impediments for the fieldwork and possible adaptations. For this, we conducted a data collection using forms prepared on the Google Forms digital platform, sent via electronic mail. A total of 207 students participated, referring to 18 graduate programs, from the five regions of the country. The results revealed that $59.4 \%$ of the students completely suspended field activities in the first 12 months of the pandemic, while others had to make drastic decisions, including the exclusion of fieldwork. The extension of deadlines is necessary for the completion of the surveys, notably those where there were no possibilities for adjustments and adaptations.

Keywords: Postgraduate research, Geographic knowledge, Public health crisis.

\footnotetext{
${ }^{1}$ Doutoranda em Geografia pela Universidade Estadual do Ceará (UECE). Email: andreacesar2009@hotmail.com

${ }^{2}$ Professor do Departamento de Geografia da Universidade Estadual do Ceará (UECE). Email: fred.holanda@uece.br
} 


\section{INTRODUÇÃO}

Em 30 de janeiro de 2020 a Organização Mundial de Saúde (OMS) declara Emergência em Saúde Pública de Interesse Internacional (Public Health Emergency of Internacional Concern - PHEIC), o mais alto nível de emergência da OMS, devido à disseminação de Covid- $19^{3}$ em diversos países (WHO, 2021a). Em pouco tempo a situação se caracterizou como pandemia, anunciada em 11 de março de 2020 pela OMS (OPAS/OMS, 2020). No início, como se tratava de uma doença desconhecida, sem dados precisos acerca da transmissão, sintomas, tratamento e imunidade, o distanciamento social se tornou a medida mais indicada por governos e autoridades sanitárias, sobretudo após o avanço dos casos, a velocidade de transmissões e o número de vítimas fatais (KISSLER et al., 2020).

O distanciamento social, como forma de conter a transmissão da doença, impôs regras rígidas de isolamento social e paralização dos serviços de transporte e das atividades educacionais, recreativas, religiosas e econômicas, funcionando apenas as consideradas essenciais e aquelas destinadas a dar suporte ao combate à doença. Apesar das possíveis consequências negativas decorrentes destas medidas, elas se mostraram necessárias e urgentes, uma vez que o ritmo da mobilidade espacial contemporânea foi importante fator da rápida expansão da doença, como apontam Sposito e Guimarães (2020), contribuindo para o esgotamento do sistema de saúde nos mais diversos países.

Durante a pandemia, ainda em curso, diversas reflexões têm sido apresentadas 4 pela comunidade científica, em diferentes campos do saber, acerca dos impactos até agora provocados e das consequências que ainda podem surgir. No que se refere à Geografia, Haesbaert (2020), corroborando com Sposito e Guimarães (2020), comenta que a pandemia de Covid-19 revela diversas problemáticas de ordem geográfica, onde muitos recortes podem ser estabelecidos.

De fato, as contribuições da Geografia para o debate perpassam pelos mais variados temas incluindo a dinâmica e propagação da doença em rede urbana (PEREIRA JÚNIOR; SAMPAIO; GOMES, 2020; SPOSITO; GUIMARÃES, 2020; TEIXEIRA; SOUZA, 2020; PAULA et al., 2020); espacialidade na oferta dos serviços de saúde (BESSA; LUZ, 2020); distanciamento social na perspectiva do espaço sagrado (SANTOS FILHO; COSTA, 2020a; 2020b); implicações no fluxo aéreo (OLIVEIRA; CASTILHO, 2020; PEREIRA et al., 2020); espacialização entre povos indígenas (FOSCHIERA; SILVA, 2020); Covid-19 no discurso político (PFRIMER; BARBOSA JÚNIOR, 2020); gestão e políticas públicas (FREITAS; NUNES; SILVA, 2020); dentre outros, citando apenas publicações em âmbito nacional. Estes e outros trabalhos podem ser conferidos na plataforma Observatório Geográfico sobre os impactos da COVID-19, lançado pela Associação dos Geógrafos Brasileiros (AGB).

Neste artigo, nos propomos a investigar os impactos da pandemia em âmbito acadêmico, com foco nos trabalhos de campo das pesquisas de pós-graduação em Geografia no Brasil. O objetivo foi tentar verificar quais os principais impedimentos e as possíveis adaptações, tendo em vista as restrições de mobilidade e de interação social impostas. A pesquisa se ampara metodologicamente em revisão bibliográfica e na coleta

\footnotetext{
${ }^{3}$ A Covid-19 é um tipo de Síndrome Respiratória Aguda Grave (SARS) provocada pelo vírus SARS-CoV-2 (novo coronavírus) e transmitida pelas vias aéreas e contato próximo com pacientes infectados, incluindo pessoas assintomáticas (ZHENG et al., 2020).

${ }^{4}$ Nas Ciências da Saúde, por exemplo, foi criada a plataforma PUBCOVID19, que reúne artigos indexados nas plataformas Pubmed e EMBASE, classificados por tema.
} 
de dados obtidos por meio de formulários elaborados na plataforma digital Google Forms, cujo link foi encaminhado via correio eletrônico para os programas de pós-graduação.

O texto está dividido em duas partes: primeiramente relacionamos breves considerações acerca da importância do trabalho de campo na produção do conhecimento geográfico; em seguida, são apresentados e discutidos os resultados da consulta realizada com alunos de pós-graduação em Geografia de diversas universidades brasileiras sobre os impactos da pandemia de Covid-19 em seus trabalhos de campo.

\section{O PAPEL DO TRABALHO DE CAMPO NA PESQUISA GEOGRÁFICA}

$\mathrm{Na}$ execução da pesquisa acadêmica os procedimentos metodológicos ditam os meios para alcançar os objetivos propostos e, dentre eles, o trabalho de campo se constitui como etapa tão fundamental quanto o trabalho de gabinete. A realização do trabalho de campo concretiza o encontro do pesquisador com o seu objeto de estudo, possibilitando não somente a coleta de dados primários, mas também a apreensão de aspectos dificilmente vislumbrados apenas por meio das leituras e reflexões (CRUZ, 1997; CLAVAL, 2013).

Para que esse encontro pesquisador-campo possa acarretar resultados satisfatórios temos que considerar duas questões importantes: primeiramente, o propósito do trabalho de campo precisa estar devidamente articulado com a teoria e o método escolhidos, o que irá influenciar na forma como será executado (SUERTEGARAY, 2002; ALENTEJANO; ROCHA-LEÃO, 2006). A outra questão se refere ao planejamento, que deve contemplar, dentre outros aspectos, a definição dos objetivos da busca em campo; um roteiro bem estruturado das atividades a serem realizadas; agendamentos prévios com informantes-chave, quando for o caso; e sobretudo um cronograma flexível que considere possíveis imprevisibilidades (CRUZ, 1997). Planejar o campo é uma atividade trabalhosa que pode demandar horas e até dias para sua elaboração, no entanto, é essencial para aplicar melhor o tempo e os recursos disponíveis. Considerando que o planejamento deverá ocorrer após o levantamento bibliográfico e cartográfico, onde obtemos os dados lançados pelo olhar de outros pesquisadores, entende-se o trabalho de campo como "a fonte de toda observação e interpretação nova" (RUELLAN, 1956, p. 74).

Assim, com as atividades de campo devidamente sistematizadas, o pesquisador parte para a obtenção dos dados primários, que pode ser realizada de diferentes formas, mas, em geral, ela acontece com a participação de diversos atores envolvidos direta ou indiretamente no processo, sobretudo quando o pesquisador não tem conhecimento prévio da área. O contato direto com comerciantes locais; guias e condutores de turismos; representantes do poder público local; líderes comunitários; funcionários da rede hoteleira e/ou moradores é sempre uma importante fonte de informação, mesmo quando o objeto de estudo são os aspectos físicos do território. Quando o trabalho inclui a prática da observação participante em comunidades esse contato é mais intenso e prolongado e, neste caso, a transmissão do conhecimento dos informantes-chave se torna a base para a leitura do fenômeno observado. Em ambos os casos, se deve valorizar a memória e as percepções dos habitantes como uma importante interpretação da realidade por eles vivida e em perpétua interação (SANTOS, 1999) e que colabora com a gênese das reflexões científicas por meio da troca de ideias (LACOSTE, 1977).

Vale ressaltar que, para melhor aproveitamento do tempo em campo, os materiais utilizados, tanto os técnicos como aqueles elaborados pelo pesquisador (como fichas de campo ou questionários) devem possibilitar a coleta da maior quantidade possível de dados. E, para otimizar a apreensão das informações adquiridas, estes dados - por mais 
exaustivos que tenham sido o percurso e as atividades realizadas - devem ser analisados logo após o retorno, quando as lembranças estão recentes e, portanto, mais fácil de resgatar as experiências vivenciadas em campo (OLIVEIRA; MARTINELLI, 2007). No entanto, no momento em que ocorre o confronto das ideias preconcebidas com a realidade observada in loco, por lacunas do conhecimento ou carência de informações, pode surgir a necessidade de voltar a campo para esclarecimentos, ajustes e confirmações, de maneira que possibilite a correta reprodução do fenômeno estudado (TRICART, 1977). Este fato, desde que tenham sido previstas flexibilidades no cronograma, não deve ser encarado como um problema, mas sim como uma possibilidade de aprimorar o conteúdo da pesquisa.

O papel do trabalho de campo na pesquisa geográfica já foi tratado por muitos autores que ratificam a necessidade do encontro pesquisador-campo para a validação de dados e novas descobertas. Claval (2013) acredita que

sem a experiência prática, o geógrafo deixa escapar uma parte essencial das realidades que ele tem a intenção de dar conta: aquelas que não são fruto da inteligência, mas da intuição, da sensibilidade, do gosto, da estética: aquelas que revelam a diferenciação qualitativa do mundo (CLAVAL, 2013, p. 4).

Cruz (1997, p. 93) ressalta quatro aspectos que justificam o trabalho de campo como "estratégia importante de análise, muitas vezes imprescindível": 1) a dinâmica inerente da natureza e da sociedade, que com o tempo pode defasar toda a bibliografia produzida sobre determinado fenômeno ou lugar; 2) a questão da subjetividade, com a ida ao campo o pesquisador tem suas próprias percepções; 3) a necessidade de se construir ou aprimorar base de dados; e, por fim, 4) a existência de informações que só podem ser obtidas no campo.

Neste sentido, todo o esforço empregado para a realização do trabalho de campo tem sua recompensa quando se concebe uma nova leitura sobre a realidade estudada, se constituindo como uma experiência enriquecedora, inclusive para o amadurecimento intelectual do pesquisador (CRUZ, 1997). No entanto, com base na participação pessoal em bancas de defesa de dissertações e teses, Rio (2011) observou em muitas delas que as considerações acerca do trabalho de campo são praticamente ignoradas e, quando ocorrem, são de modo superficial, em detrimento da atenção dispensada aos equipamentos levados a campo, ficando ausentes as reflexões sobre o papel desta etapa metodológica. Lacoste-Dujardin (1977) também destacou que na maioria das vezes, apenas os resultados das pesquisas são divulgados e discutidos, enquanto o processo pelo qual esse resultado foi obtido, permanece desconhecido, e compara com a divulgação dos resultados pelos pesquisadores das Ciências Exatas, que consideram essencial detalhar minuciosamente o processo metodológico. A autora acredita ser válido expor inclusive "os desvios e os acontecimentos que envolveram a investigação" (LACOSTE-DUJARDIN, 1977, p. 23).

O relato (e a publicação) das experiências em campo pode ser interessante na medida em que colabora para o aperfeiçoamento de técnicas, instrumentos e metodologias empregadas, bem como para discutir seus limites e possibilidades. No que concerne especificamente aos "desvios e acontecimentos" - imprevistos que deverão ser considerados no cronograma do planejamento (CRUZ, 1997) - alguns poderão ser contornados sem o comprometimento de prazos e resultados, já outros poderão afetar, sobremaneira, e até mesmo inviabilizar atividades em campo, independente da criatividade, recursos e tempo disponível do pesquisador. Os imprevistos que acometem o 
trabalho de campo podem ser desde aqueles de ordem pessoal (como perda de financiamento, doença ou luto), como também mudanças bruscas nas condições meteorológicas, entraves burocráticos, cancelamento de entrevistas, dentre outros que podem comprometer o andamento da pesquisa como um todo.

E quando o imprevisto é de ordem global? Como dar seguimento ao trabalho de campo com rígidas restrições de deslocamento e contatos interpessoais impostos pela pandemia de Covid-19? Quais as possíveis adaptações frente a tantas incertezas e prazos a cumprir? Em 2020, o risco de contágio da Covid-19 gerou obstáculos inimagináveis para o trabalho de campo em diversos campos da ciência.

\section{IMPACTOS DA PANDEMIA DE COVID-19 NA ETAPA DE TRABALHO DE CAMPO DA PÓS-GRADUAÇÃO EM GEOGRAFIA}

Durante a pandemia de Covid-19 a comunicação remota tem sido fundamental para driblar as inconveniências do distanciamento social e, em alguns casos, se tornou condição sine qua non para dar prosseguimento às atividades da vida social. Na pesquisa acadêmica não foi diferente, as redes sociais e plataformas digitais têm amparado a comunicação entre os diversos atores envolvidos no processo de produção do conhecimento.

Neste contexto, a coleta de dados primários deste estudo foi realizada por intermédio de um questionário desenvolvido na plataforma digital Google Forms, composto de 16 perguntas. A consulta, de natureza anônima, ficou disponível no período de seis semanas, entre 19 de janeiro e 2 de março de 2021. Inicialmente o link do questionário foi enviado via correio eletrônico para as secretarias ou coordenações de 58 programas de pós-graduação em Geografia no Brasil, com a solicitação de encaminhamento para o corpo discente. A participação dos programas, portanto, foi fundamental para o alcance do público-alvo. Os programas de pós-graduação foram identificados a partir de dados disponíveis no website da Associação Nacional de Pósgraduação em Geografia (ANPEGE), contemplando programas do DF e dos 26 estados da federação.

Os 207 alunos participantes correspondem a 18 programas, de 14 estados (51,85\%) brasileiros, sendo dois da Região Norte (Pará e Rondônia), sete da Região Nordeste (Piauí, Maranhão, Ceará, Bahia, Paraíba, Rio Grande do Norte e Alagoas), um da Região Centro-Oeste (Mato Grosso do Sul), dois da Região Sudeste (Rio de Janeiro e São Paulo), e dois da Região Sul (Paraná e Santa Catarina), contemplando assim, todas as cinco regiões do país. No total $55,1 \%$ (114) dos participantes são alunos de mestrado e $44,9 \%$ (93) de doutorado.

A consulta revelou que a Geografia Ambiental é o segmento com maior número de pesquisas em desenvolvimento, 49 no total, seguidos de 32 na Geografia Urbana; 25 na Geografia Agrária; 22 na Geomorfologia; 14 na Geografia Econômica; 11 Geografia Cultural; 8 em Biogeografia; oito em Climatologia; sete em Geografia do Turismo; sete em Ensino de Geografia; dentre outros em menor quantidade.

Quanto à bolsa de estudos, apenas 52,7\% (109) dos recebem financiamento para custear a pesquisa. Verificamos também que 17,7\% (36) estão inseridos em programas que não prorrogam os prazos de qualificação e defesa das dissertações e teses. A falta de financiamento está entre os fatores que dificultam o desenvolvimento de pesquisas na pós-graduação e, no contexto da pandemia, a não expansão dos prazos torna ainda mais penoso este processo. Em termos de gestão da pós-graduação nacional, pode-se destacar que, de um lado foram criadas alternativas de flexibilização de prazos de 
elaboração de pesquisas e defesas, tais como a extensão de bolsas por um período de até três meses e a retirada do critério de período de defesa na pontuação da avaliação quadrienal (Portaria CAPES No. 55/2020, alterada pela Portaria No. 121/2020). Por outro lado, diversas medidas têm tornado a pesquisa no âmbito da pós-graduação brasileira cada vez mais restritas, sobretudo no âmbito das Ciências Humanas, no qual a Geografia faz parte. Além disso, o atual critério de distribuição de bolsas (Portaria CAPES No. 28/2021) tende a contribuir com uma maior concentração de recursos nos centros de pesquisa já consolidados.

Quando questionados sobre interrupção do trabalho de campo 7,2\% (15) dos alunos informaram que não interromperam seus trabalhos de campo; $11,1 \%$ (23) já haviam realizado a etapa de campo ou ela não estava prevista para ocorrer em 2020, verificamos que neste grupo se encontram alunos no início ou no final dos cursos; outros $7,2 \%$ (15) interromperam o trabalho de campo por mais de quatro meses; $15 \%$ (31) interromperam por mais de oito meses; e 59,4\% (123) informaram que o trabalho de campo ainda estava interrompido. A distribuição destes resultados, por curso, é apresentada na Tabela 1.

Tabela 1. Interrupção nos trabalhos de campo entre mar/2020 e fev/2021

\begin{tabular}{|c|c|c|c|c|c|c|}
\hline \multirow[t]{2}{*}{ Curso } & \multicolumn{3}{|c|}{ Trabalho de campo interrompido } & \multirow{2}{*}{$\begin{array}{l}\text { Trabalho de } \\
\text { campo já } \\
\text { realizado ou } \\
\text { não previsto } \\
\text { para } 2020\end{array}$} & \multirow{2}{*}{$\begin{array}{c}\text { Não } \\
\text { Interrom- } \\
\text { peram o } \\
\text { trabalho } \\
\text { de campo }\end{array}$} & \multirow[t]{2}{*}{ Total } \\
\hline & $\begin{array}{c}\text { por mais } \\
\text { de } \\
4 \text { meses }\end{array}$ & $\begin{array}{l}\text { por mais } \\
\text { de } \\
8 \text { meses }\end{array}$ & $\begin{array}{c}\text { ainda } \\
\text { está } \\
\text { interrompido }\end{array}$ & & & \\
\hline Mestrado & $\begin{array}{c}9 \\
(7,9 \%)\end{array}$ & $\begin{array}{c}19 \\
(16,6 \%)\end{array}$ & $\begin{array}{c}64 \\
(56,1 \%)\end{array}$ & $\begin{array}{c}13 \\
(11,5 \%)\end{array}$ & $\begin{array}{c}9 \\
(7,9 \%)\end{array}$ & 114 \\
\hline Doutorado & $\begin{array}{c}6 \\
(6,5 \%)\end{array}$ & $\begin{array}{c}12 \\
(12,9 \%)\end{array}$ & $\begin{array}{c}59 \\
(63,4 \%)\end{array}$ & $\begin{array}{c}10 \\
(10,7 \%)\end{array}$ & $\begin{array}{c}6 \\
(6,5 \%)\end{array}$ & 93 \\
\hline $\begin{array}{c}\text { Total } \\
(\%)\end{array}$ & $\begin{array}{c}15 \\
(7,2 \%)\end{array}$ & $\begin{array}{c}31 \\
(15 \%)\end{array}$ & $\begin{array}{c}123 \\
(59,4 \%)\end{array}$ & $\begin{array}{c}23 \\
(11,1 \%)\end{array}$ & $\begin{array}{c}15 \\
(7,2 \%)\end{array}$ & $\begin{array}{c}207 \\
(100 \%)\end{array}$ \\
\hline
\end{tabular}

Fonte: Elaborado pelos autores, 2021

Podemos supor que tais resultados estão atrelados às restrições de mobilidade espacial, interação social e pela paralização dos serviços socioeconômicos, que incluem a rede hoteleira e de transporte, tão necessárias na realização dos trabalhos de campo. Especificamente, quanto às questões de deslocamento e hospedagem, verificamos que $50,72 \%$ (105) dos alunos precisariam de viagens com hospedagem na área de estudo, sendo $32,4 \%$ (67) de viagens intermunicipais; $12,6 \%$ (26) interestaduais; e 5,8\% (12) internacionais; os demais, com área de estudo no município onde residem ou próximo, não necessitariam de hospedagem.

No que se refere ao contato com público-alvo e área de estudo, para 69,6\% (144) dos alunos, estava previsto contato direto com grupos em centros urbanos, industriais, comerciais, escolas ou outros ambientes com aglomerações humanas. Outros 26,6\% (55) teriam contato com populações tradicionais (quilombolas, indígenas, caiçaras etc.) relativamente isoladas. Quanto ao acesso à área de estudo, 51,2\% (106) dos alunos realizariam campo em propriedade privada e/ou área protegida com acesso controlado. Para aqueles que precisam do contato com populações tradicionais em área protegida federal ficou inviável a realização do trabalho de campo, visto que o Instituto Chico 
Mendes de Conservação da Biodiversidade (ICMBio), suspendeu, no dia 17 de março de 2020, a visitação às unidades de conservação federais (UCs). A reabertura para visitação aconteceu, de forma gradual, a partir do dia 28 de agosto de 2020, e mediante o cumprimento dos protocolos sanitários. No entanto, as UCs que abrigam populações tradicionais não foram liberadas para visitação (ICMBIO, 2021), visto que constituem grupo de risco

Quanto ao contágio da Covid-19, 13,1\% (27) afirmaram que foram vítimas da doença de forma sintomática, 3,9\% (8) de forma assintomática. No que se refere à saúde emocional dos discentes, 61,7\% (127 alunos) responderam que sofreram (ou ainda estão sofrendo) com algum tipo de transtorno emocional (depressão, síndrome do pânico, crise de ansiedade etc.) decorrente da pandemia. Estudos revelam que os alunos de pósgraduação já estão sujeitos a sofrer transtornos emocionais decorrentes de elevados níveis de estresse devido às fortes pressões e cobranças sofridas durante o curso, notadamente por fatores como: alta competitividade, prazos a cumprir, incertezas quanto ao futuro profissional, processos de avaliação (intercâmbios, qualificação e defesa), dificuldades no relacionamento com orientadores, cobrança de produtividade, preocupações com a obtenção de bolsa ou financiamento, dentre outros (MALAGRIS et al., 2009). Tais fatores, somados às circunstâncias dramáticas vivenciadas pela pandemia - que forçaram os indivíduos a adequar a vida profissional e familiar para um contexto de confinamento sem planejamento prévio - provavelmente colaboraram para 0 alto percentual de alunos com algum transtorno emocional, tendo em vista que muitos destes fatores foram agravados pela crise de saúde pública global.

Neste cenário, na avaliação dos próprios alunos, podemos verificar diferentes níveis de impactos provocados pela pandemia (Figura 1), não somente na realização dos trabalhos de campo, mas na pesquisa como um todo:

1) $5,3 \%$ (11) dos alunos responderam que a pandemia 'não impactou' no seu mestrado/doutorado. No entanto, neste grupo há aqueles que adoeceram de forma sintomática, tiveram transtorno emocional, precisaram fazer adaptações, e/ou tiveram trabalho de campo interrompido por pelo menos quatro meses;

2) para $23,7 \%$ (49) 'impactou pouco'. Entre eles encontram-se aqueles fora da fase de campo, dedicando-se a revisão bibliográfica, e outros em fase de finalização do curso;

3) $54,6 \%$ (113) consideram que 'impactou muito, mas puderam adaptar algumas atividades'; e

4) para 16,4\% (34) dos alunos a pandemia 'impactou muito, inviabilizando qualquer tipo de atividade'. Destes 34 alunos, observamos que 27 realizariam campo em ambientes com aglomerações (comércio, fábricas, escolas etc.); 23 precisariam de deslocamentos com hospedagem, incluindo dois alunos com viagens internacionais programadas; 19 sofreram ou ainda estão sofrendo com algum transtorno emocional; 18 tem objeto de estudo em área de acesso controlado; 15 tem populações isoladas como público-alvo; e outros 15 não puderam adaptar seus trabalhos.

Nota-se que, para a grande maioria houve impacto da pandemia de Covid-19 na realização dos trabalhos de campo e/ou no andamento das pesquisas como um todo. No entanto, na tentativa de driblar os obstáculos provocados por esse grande imprevisto de dimensão global, muitos alunos fizeram adaptações para dar conta dos prazos a cumprir. $\mathrm{E}$ para verificar quais os tipos de adaptação por eles realizadas, elencamos 4 possíveis alterações na pesquisa: redução ou mudança da área de estudo; redução ou exclusão do 
público-alvo ou contato com população local; opção por contatos com informantes-chave via plataformas digitais; e troca do tema.

Figura 1. Níveis de impactos da pandemia nas pesquisas de pós-graduação em Geografia, em 2020

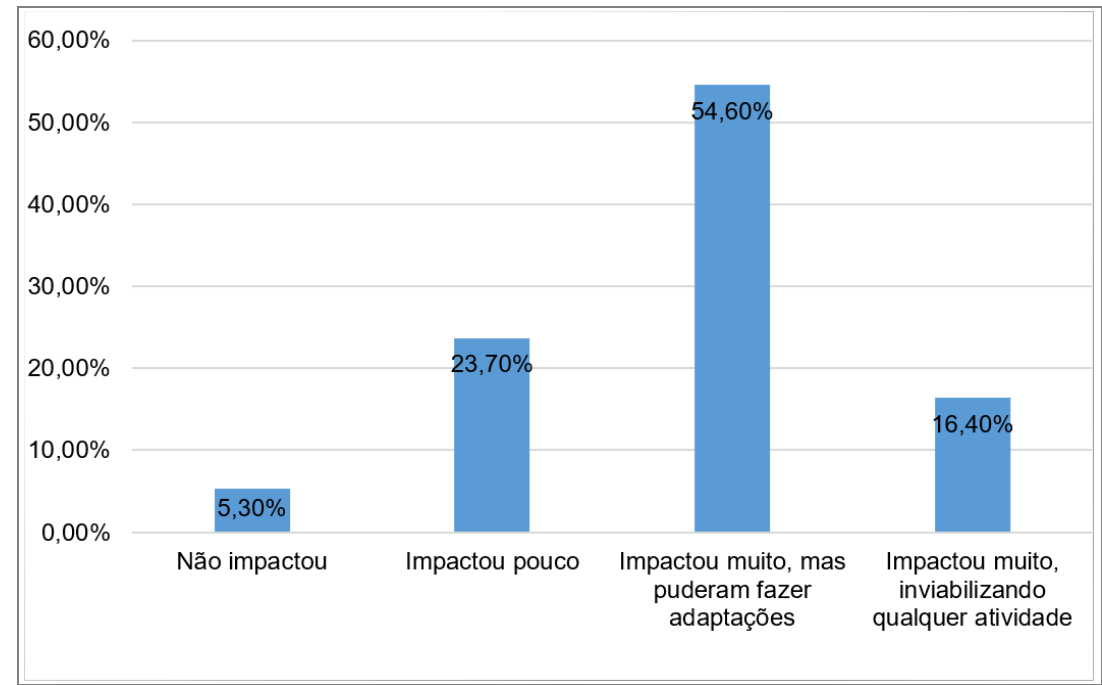

Fonte: Elaborada pelos autores, 2021

Considerando que outras adaptações poderiam ocorrer, deixamos opção para o relato espontâneo, onde verificamos que alguns alunos ainda estão decidindo se farão adaptações, enquanto outros tomaram decisões drásticas como a troca do objeto de estudo, troca da metodologia, exclusão ou redução de análises laboratoriais e até mesmo a exclusão da etapa de campo. Nos relatos, verificamos também que os impactos para os trabalhos de campo ocorreram mesmo naquelas pesquisas onde estes já foram realizados, mas que precisariam do tratamento do material coletado em campo, inviabilizando a obtenção dos resultados e, consequentemente, da discussão e conclusão das pesquisas. Um(a) mestrando(a) que trabalha com a temática Hidrogeologia relatou que "Os dados obtidos em campo foram completamente prejudicados"; outro(a) doutorando(a), que desenvolve pesquisa em Biogeografia, declarou: "Minha etapa de campo foi finalizada em 2019, mas toda minha fase laboratorial bioquímica está parada desde março do ano de 2020, e sem perspectiva de retorno, pois esses experimentos faço em universidades externas e todas estão com seus laboratórios fechados". Em outro caso, um(a) mestrando(a), com trabalho em Geoarqueologia, revelou que fará "mudança de datas e, provavelmente, exclusão de algumas análises".

O panorama geral das adaptações realizadas pelos alunos consultados neste trabalho pode ser visualizado na Tabela 2. No total, os resultados mostraram que a maioria dos alunos, 63,7\% (132), realizaram uma ou mais adaptações; 34,5\% (71) não realizaram nenhuma adaptação; e 3,4\% (7) ainda estão decidindo sobre possíveis adaptações.

Vale ressaltar que, apesar de não desejáveis, alterações como as elencadas acima, dentre outras, são passíveis de acontecer ao longo de um curso de pósgraduação. No entanto, no contexto da pandemia de Covid-19, ao se debruçar sobre as possibilidades de adaptação, o pesquisador certamente se deparou com dois fatores importantes a serem considerados: sazonalidade e tipo de público-alvo.

A sazonalidade do fenômeno a ser observado recai tanto na esfera da pesquisa social, como nas análises ambientais. Festas e manifestações culturais ou religiosas de 
periodicidade anual, por exemplo, não puderam ser acompanhadas durante a pandemia devido ao cancelamento dos eventos com aglomerações humanas. Nos estudos ambientais, pesquisas que dependiam do período de floração de determinada espécie; da presença de aves migratórias; ou da caracterização dos períodos de vazão dos cursos d'água, por exemplo, foram comprometidas, sobretudo aquelas que ocorreriam dentro de áreas com acesso controlado.

Tabela 2. Panorama das adaptações realizadas nas pesquisas geográficas em 2020

\begin{tabular}{lcc}
\hline Com adaptações & 132 & $\mathbf{6 3 , 7 \%}$ \\
\hline Redução ou mudança da área de estudo & 33 & $15,9 \%$ \\
\hline Redução ou exclusão do público-alvo ou população local & 40 & $19,3 \%$ \\
\hline Opção por contatos com público-alvo via plataformas digitais & 39 & $18,8 \%$ \\
\hline Troca do tema & 9 & $4,3 \%$ \\
\hline Troca de objeto de estudo & 1 & $0,5 \%$ \\
\hline Troca de metodologia & 3 & $1,4 \%$ \\
\hline Exclusão ou redução de análises laboratoriais & 2 & $1 \%$ \\
\hline Exclusão do trabalho de campo & 5 & $2,4 \%$ \\
\hline Sem adaptações & 71 & $\mathbf{3 4 , 5} \%$ \\
\hline Ainda não sabem se farão adaptações & 7 & $\mathbf{3 , 4} \%$ \\
\hline
\end{tabular}

Fonte: Elaborada pelos autores, 2021

Quanto às alterações no público-alvo, as possibilidades de adaptações esbarram em algumas limitações metodológicas. Com as restrições de contato, a utilização de meios de comunicação remota tornou-se uma forma viável de coleta de dados, entretanto, existe o problema da baixa taxa de participação, apontada como uma das desvantagens da coleta de dados online (EVANS; MATHUR, 2005). Este fato verificamos neste trabalho, que contou com apenas 31\% (18) dos 58 programas de pós-graduação contactados. Outra desvantagem da comunicação remota é que ela não se adequa a todos os tipos de público-alvo, tendo em vista que nem todos têm acesso e/ou habilidades com as plataformas de comunicação remota via internet. Para a pesquisa com populações tradicionais isoladas, estudantes de escola pública ou populações institucionalizadas, por exemplo, pode haver barreiras na comunicação. Tais questões podem ter contribuído para que alguns alunos tenham optado pela redução ou exclusão do público-alvo e pela troca de tema ou objeto de estudo.

Há de se considerar também que qualquer mudança, seja de tema, metodologia ou objeto/área de estudo, fica de certa forma condicionada a etapa em que a pesquisa se encontra, se no início, meio ou fim do curso. Quanto mais próximo da conclusão, mais difícil se torna a decisão de alterar o que foi firmado no projeto de dissertação ou tese ou de desconsiderar o que já foi concluído.

Por outro lado, quem estava iniciando a pós-graduação e pôde adequar o tema ao contexto da pandemia ficou menos prejudicado, tendo em vista que ela abriu um leque de questões novas a serem trabalhadas, notadamente no campo da Antropologia, Sociologia e Ciências da Saúde. Na Geografia, onde isso não for possível, apesar da inegável importância do trabalho de campo na produção do conhecimento geográfico, muitos alunos de pós-graduação (e graduação) terão que abrir mão deste procedimento metodológico. Porém, para compensar a falta do trabalho de campo, deverão reforçar o 
conteúdo de seus trabalhos na revisão bibliográfica, extrair o máximo possível de dados secundários e, notadamente, de recursos como geoprocessamento e plataformas digitais, que certamente serão ferramentas indispensáveis neste contexto de distanciamento social. Dada a dimensão dos impactos negativos provocados pela pandemia, também vale considerar e compartilhar, tal como sugerido por Lacoste-Dujardin (1977) e Rio (2011), nas discussões e considerações dos trabalhos, as adversidades sofridas em 2020.

Muitos dos participantes desta pesquisa ainda não fizeram nenhuma adaptação em suas pesquisas na espera de oportunidade segura, no entanto, logo será necessária a tomada de decisão, visto que o início de 2021 assiste ao pior momento da pandemia de Covid-19 no Brasil, que é o terceiro país no mundo em números de casos confirmados e o segundo em número de mortes (WHO, 2021b). Na primeira semana de março os casos diários são $30 \%$ mais altos do que na primeira onda da pandemia, em julho de 2020, e cientistas alertam para uma terceira onda da doença, ainda mais intensa (AZEVEDO, 2021).

\section{CONSIDERAÇÕES FINAIS}

Este artigo teve o intuito de contribuir para a discussão acerca do papel do trabalho de campo na pesquisa geográfica, bem como dos efeitos da pandemia de Covid-19 no contexto acadêmico. Os resultados mostraram que os transtornos provocados pela pandemia - sem precedentes nesta geração - afetaram as pesquisas de diferentes formas, obrigando os alunos a realizar ajustes nas pesquisas para garantir o cumprimento dos prazos sem comprometer a qualidade de suas dissertações e teses. No entanto, devido a realidades distintas, nem todos efetuaram adaptações em seus trabalhos.

A pós-graduação no Brasil vem sofrendo um impacto expressivo por conta do distanciamento social decorrente do atual contexto da pandemia. No caso da Geografia esse impacto pode ser claramente observado na realização dos trabalhos de campo, além de outros aspectos mais particulares. Conforme mencionado anteriormente os trabalhos de campo constituem etapa fundamental no desenvolvimento da pesquisa geográfica, nas suas mais diversas abordagens epistemológicas.

Frisamos aqui a importância da prorrogação de prazos de qualificação e defesa pelos programas de pós-graduação, para que os alunos possam realizar os ajustes necessários e dar seguimento as etapas restantes para a conclusão de seus trabalhos, considerando o abalo emocional, tão típico da pós-graduação, e que se somou às calamidades da pandemia.

No momento em que encerramos a redação deste texto - às vésperas de completar um ano da declaração da pandemia de Covid-19 - o Brasil amarga 268.370 mortes e uma nova variante da doença surge entre nós. No entanto, com o rápido desenvolvimento de vacinas e o início de sua aplicação, podemos ter esperança de em breve retomarmos nossas atividades com segurança. Até lá, cabe a nós confiarmos na ciência.

\section{AGRADECIMENTOS}

À Coordenação de Aperfeiçoamento de Pessoal de Nível Superior (CAPES), pela concessão de bolsa de doutorado concedida ao primeiro autor. 


\section{REFERÊNCIAS BIBLIOGRÁFICAS}

ALENTEJANO, P. R. R.; ROCHA-LEÃO, O. M. Trabalho de campo: uma ferramenta essencial para os geógrafos ou um instrumento banalizado? Boletim Paulista de Geografia, SÃO PAULO, o 84, p. 51-67, 2006. Disponível em:<https://www.agb.org.br/publicacoes/index.php/boletim-paulista/issue/view/57>.

Acesso em: 03 fev. 2021.

AZEVEDO, A. L. Casos diários de Covid-19 já são $30 \%$ mais altos do que no pico de 2020. O Globo, Rio de Janeiro, 8 mar. 2021. Disponível em: <https://oglobo.globo.com/sociedade/coronavirus/casos-diarios-de-covid-19-ja-sao-30mais-altos-do-que-no-pico-de-2020-24914212>. Acesso em: 8 mar. 2021.

BATISTA, M. D. G. Pesquisa na internet: considerações metodológicas. In: Encontro de Ciências Sociais do Norte e Nordeste e pré-alas Brasil, 15, 2012, Teresina, Piauí. Anais [...] Teresina, 2012, não paginado. Disponível em: <https://www.researchgate.net/profile/Micheline_Batista/publication/258033295_Pesquisa na_internet_consideracoes_metodologicas/links/00463526b03b7a7e1b000000.pdf >. Acesso em: 19 fev.2021.

BESSA, K.; LUZ, R. A. A Covid-19 e a desigual espacialidade na oferta de serviços de saúde no segmento da rede urbana regional do estado do Tocantins, Brasil. Edição especial, Caminhos de Geografia, Uberlândia, p. 144-163, dez. 2020.

CRUZ, R. C. A. Os caminhos da pesquisa de campo em Geografia. Geousp - Espaço e Tempo, v. 1, n. 1, p. 93-97, 1997. Disponível em: <https://www.revistas.usp.br/geousp/issue/view/9229>. Acesso em: 29 jan. 2021.

EVANS, J. R.; MATHUR, A. The value of online surveys. Internet Research, v. 15, n. 2, p.195-219, 2005.2 Disponível em: <https://www.emerald.com/insight/content/doi/10.1108/10662240510590360/full/html>. Acesso em: 1 mar. 2021.

FOSCHIERA, A. A.; SILVA, J. S. A espacialização da Covid-19 nos Distritos Sanitários Especiais Indígenas da Amazônia Legal. Ateliê Geográfico, Goiânia, v. 14, n. 3, p. 6-34, dez. 2020. Disponível em: < https://www.revistas.ufg.br/atelie/article/view/65329/36314>. Acesso em: 1 fev. 2021

FREITAS, E. S. M.; NUNES, M. S.; SILVA, P. E. A. B. A materialidade geohistórica e epidemiológica da COVID-19: reflexões e análises no contexto da Região Metropolitana de Belo Horizonte. Boletim Goiano de Geografia, v. 40, n. 1, p. 1-26, 2020. Disponível em: <https://revistas.ufg.br/bgg/article/view/63845>. Acesso em: 1 fev. 2021.

HAESBAERT, R. Reflexões geográficas em tempos de pandemia. Espaço e Economia, Rio de Janeiro, ano 9, n. 18, p. 1-5, maio 2020. Disponível em: <https://journals.openedition.org/espacoeconomia/11826>. Acesso em: 2 fev. 2021.

INSTITUTO CHICO MENDES DE CONSERVAÇÃO DA BIODIVERSIDADE. ICMBio determina reabertura de unidades de conservação para visitas. 26 de agosto de 
2020. Disponível em: <https://www.gov.br/pt-br/noticias/meio-ambiente-eclima/2020/08/icmbio-determina-reabertura-de-unidades-de-conservacao-para-visitas $>$.

Acesso em: 5 mar. 2021.

KISSLER, S. M.; TEDIJANTO, C.; GOLDSTEIN, E.; GRAD, Y. H.; LIPSITCH, M. Projecting the transmission dynamics of SARS-CoV-2 through the postpandemic period. Science, v. 368, n. 6493, p. 860-868, maio de 2020. Disponível em: <https://science.sciencemag.org/content/368/6493/860>. Acesso em: 31 jan. 2021.

LACOSTE, Y. L'enquête et le terrain: um problème politique pour les chercheurs, les étudiants et les citoyens. Hérodote, Paris, n. 8, p.3-20, 1977. Disponível em: <https://gallica.bnf.fr/ark:/12148/bpt6k5622671r?rk=42918;4>. Acesso em: 7 fev. 2021.

LACOSTE-DUJARDIN, C. La relation d'enquête. Hérodote, Paris, n. 8, p. 21-44, 1977. Disponível em: <https://gallica.bnf.fr/ark:/12148/bpt6k5622671r?rk=42918;4>. Acesso em: 8 fev. 2021.

MALAGRIS, L. E. N.; SUASSUNA, A. T. R.; BEZERRA, D. V.; HIRATA, H. P.; MONTEIRO, J. L. F.; SILVA, L. R.; LOPES, M. C. M.; SANTOS, T. S. Níveis de estresse e características sociobiográficas de alunos de pós-graduação. Psicologia em Revista, Belo Horizonte, v. 15, n. 1, p. 184-203, 2009. Disponível em: <http://pepsic.bvsalud.org/scielo.php?script=sci_arttext\&pid=S1677$11682009000200012>$. Acesso em: 3 mar. 2021.

OLIVEIRA, I. J; MARTINELLI, M. O uso dos mapas no trabalho de campo em Geografia Física. Geografia, Rio Claro, v. 32, n. 1, p. 163-179, 2007. Disponível em: <https://www.periodicos.rc.biblioteca.unesp.br/index.php/ageteo/article/view/1435>.

Acesso em: 5 fev. 2021.

OLIVEIRA, B. C.; CASTILHO, D. Entre fluxos e escalas: covid-19 e suas implicações na rede de transporte aéreo no primeiro semestre de 2020. GEOgraphia, Niterói, v. 22, n. 49, p. 1-15, 2020. Disponível em: <https://periodicos.uff.br/geographia/article/view/45882>. Acesso em: 1 fev. 2021.

ORGANIZAÇÃO PAN-AMERICANA DA SAÚDE/ORGANIZAÇÃO MUNDIAL DA SAÚDE (BRASIL). OMS afirma que COVID-19 é agora caracterizada como pandemia. 2020. Disponível em: <https://www.paho.org/bra/index.php?option=com_content\&view=article\&id=6120:omsafirma-que-covid-19-e-agora-caracterizada-como-pandemia\&ltemid=812>. Acesso em: 31 jan. 2021.

PAULA, D. P.; MEDEIROS, D. H. M.; BARROS, E. L.; GUERRA, R. G. P.; SANTOS, J. O.; LIMA, J. S. Q.; MONTEIRO, R. M. L. Diffusion of Covid-19 in the Northern Metropolis in Northeast Brazil: territorial dynamics and risks associated with Social Vulnerability. Sociedade \& Natureza, v. 32, p. 639-656, 2020. Disponível em: <http://www.seer.ufu.br/index.php/sociedadenatureza/article/view/56098>. Acesso em: 8 mar. 2021.

PEREIRA JÚNIOR, E.; SAMPAIO, J. E.; GOMES, R. A Covid-19 e a sua dinâmica de propagação na rede urbana do Ceará, Brasil. Ateliê Geográfico, Goiânia, v. 14, n. 3, 
p.35-56,

dez.

2020.

Disponível

em:

<https://www.revistas.ufg.br/atelie/article/view/66373/36288>. Acesso em: 1 fev. 2021.

PEREIRA, V. H. C.; DINIZ, M. T. M.; ROCHA, G. C.; OLIVEIRA JUNIOR, M. A. C. Identification of initial covid-19 import and dissemination routes in Brazil. Geosaberes, Fortaleza, v. 11, p. 423 - 436, julho 2020 . Disponível em: <http://www.geosaberes.ufc.br/geosaberes/article/view/1043>. Acesso em: 8 mar. 2021.

PFRIMER, M. H.; BARBOSA JÚNIOR, R. Guerra do Brasil à COVID-19: crise e não conflito - médicos e não generais. Boletim Goiano de Geografia, Goiânia, v. 40, n. 1, p. 1-9, 2020. Disponível em: <https://revistas.ufg.br/bgg/article/view/64813>. Acesso em: 1 fev. 2021.

RIO, G. A. P. Trabalho de campo na (re)construção da pesquisa geográfica: reflexões sobre um tradicional instrumento de investigação. GEOgraphia, Niterói, v. 13, n. 25, p. 42-58, 2011. Disponível em: <https://periodicos.uff.br/geographia/article/view/13615>. Acesso em: 1 fev. 2021.

RUELLAN, F. O trabalho de campo nas pesquisas originais de Geografia - Regional. Boletim Geográfico do Rio Grande do Sul, ano 1, n. 4, p. 65-74, 1956. Disponível em: $\quad<h t$ tps://revistas.dee.spgg.rs.gov.br/index.php/boletim-geograficors/article/view/3350>. Acesso em: 04 fev. 2021.

SANTOS, R. J. Pesquisa empírica e trabalho de campo: algumas questões acerca do conhecimento geográfico. Sociedade \& Natureza, Uberlândia, v. 11, n. 21-22, p. 111-125, $1999 . \quad$ Disponível em: <http://www.seer.ufu.br/index.php/sociedadenatureza/issue/view/1182>. Acesso em: 02 fev. 2021.

SANTOS FILHO, C. R.; COSTA, O. J. L. Distanciamento social na perspectiva do sagrado: coronavírus e as novas práticas espaciais. Geografia, Rio Claro, v. 45, n. 1, p. 141-162, jan./jun. 2020a. Disponível em: $<$ https://www.periodicos.rc.biblioteca.unesp.br/index.php/ageteo/article/view/15002>. Acesso em: 03 fev. 2021.

Igreja Universal e o coronavírus: a dimensão geossimbólica e a negação do isolamento social. Edição especial, Ensaios de Geografia, Niterói, v. 5, n. 9, p. 52-56, maio 2020. Disponível em: <https://periodicos.uff.br/ensaios_posgeo/article/view/42229>. Acesso em: 31 jan. 2021.

SPOSITO, M. E. B.; GUIMARÃES, R. B. Por que a circulação de pessoas tem peso na difusão da pandemia: difusão da Covid-19 no país segue modelo relacionado a interações espaciais na rede urbana. 2020. Disponível em: $<$ https://www2.unesp.br/portal\#!/noticia/35626/por-que-a-circulacao-de-pessoas-tem-pesona-difusao-da-pandemia>. Acesso em: 1 fev. 2021.

SUERTEGARAY, D. M. A. Pesquisa de campo em Geografia. GEOgraphia, Niterói, v. 4, n. 7, não paginado, 2002. Disponível em: <https://periodicos.uff.br/geographia/article/view/13423>. Acesso em: 1 fev. 2021. 
TEIXEIRA, S. H. O.; SOUZA, A. L. Análise da distribuição geográfica de covid-19 na mesorregião sul/sudoeste de Minas Gerais. Edição especial, Hygeia, p. 407-416, jun. 2020. Disponível em: <http://www.seer.ufu.br/index.php/hygeia/article/view/54632/29214>. Acesso em: 02 fev. 2021.

TRICART, J. Le terrain dans la dialectique de la géographie. Hérodote, Paris, n. 8, p. 105120, 1977. Disponível em: <https://gallica.bnf.fr/ark:/12148/bpt6k5622671r?rk=42918;4>. Acesso em: 8 fev. 2021.

WACHELKE, J.; NATIVIDADE, J.; ANDRADE, A.; WOLTER, R.; CAMARGO, B. Caracterização e avaliação de um procedimento de coleta de dados online (CORP). Avaliação Psicológica, [S.I.], v. 1, n. 13, p. 143-146, 2014. Disponível em: <https://www.redalyc.org/pdf/3350/335030683017.pdf>. Acesso em: 18 fev.2021.

WORLD HEALTH ORGANIZATION. Timeline: WHO's Covid-19 response. 2021a. Disponível em: <https://www.who.int/emergencies/diseases/novel-coronavirus2019/interactive-timeline\#!>. Acesso em: 31 jan. 2021.

WORLD HEALTH ORGANIZATION. WHO Coronavirus (COVID-19) Dashboard. 2021b. Disponível em: <https://covid19.who.int/>. Acesso em: 9 mar. 2021.

ZHENG, Q.; LU, Y.; LURE, F.; JAEGER, S.; LU, P. Clinical and radiological features of novel coronavirus pneumonia. Journal of $\mathbf{X}$-Ray Science and Technology, [S. I.]. V. 28, n. 3, p. 391-404, jun. 2020. Disponível em: <https://pubmed.ncbi.nlm.nih.gov/32538893/>. Acesso em: 04 fev. 2021. 